\section{ST. THOMAS'S HOSPITAL REPORTS.}

\section{Vol. III. 2nd Series. 1938. Price 10s. Od.}

The third volume of the second series of the St. Thomas's Hospital Report, edited by Professor De Wesselow and Mr. Max Page, gives us yet another example of the high standard that the previous volumes have led us to expect.

Among the wide variety of subjects of current interest in the fields of medicine, surgery, gynæcology, obstetrics and pathology the clinician will find much to interest him. The late Professor Dudgeon gives a complete clinical and pathological history of one of the earliest cases of X-ray carcinoma and he illustrates his points with microphotographs. Professor McSwiney, in an article on afferent fibres from the abdominal viscera details the various reflexes involving involuntary tissues and enables us to acquire some appreciation of the highly organised regulatory mechanism which is present in the central nervous system. Professor De Wesselow and Dr. Thomson deal with the important subject of sodium and potassium in Addison's disease and illustrate their subject with reports on three cases and figures for certain electrolytes in the serum and urine. Of particular practical interest are the details of a low potassium diet.

Special attention should be paid to a clinical review of the thorny subject of "gastritis" by Dr. Ingram Card. Its definition, ætiology, pathology, symptomatology, radiology and the value of gastroscopy are discussed and the correlation of these methods in diagnosis is considered. Against this, however, should be weighed the scant attention given to treatment while as far as radiology is concerned, the Berg technique is only briefly referred to and the excellent radiological work in this country of Cordiner and Calthorp is not mentioned.

Ulcerative colitis, from the point of view of prognosis is discussed by Drs. Buzzard, Richardson and Turner, but one notices but little reference to the psychological factor upon which Cullinan and Wittkower have recently laid such stress.

The biological test for Hodgkin's disease is well reviewed by Dr. King who draws the conclusion that it cannot be relied upon for an accurate diagnosis.

A very excellent review of recent work on putrid lung abscess by Mr. N. R. Barrett, containing an excellent series of radiographic and other illustrations, deserves special notice. He emphasises that those cases which do not undergo early spontaneous resolution are best treated by surgical exposure of the abscess cavity and wide open packing as soon as a reasonable chance of spontaneous resolution has passed. Although this means surgical exposure in the acute phase of the disease, modern thoracic surgery makes it a reasonably safe proposition.

The functions of a psychiatric department for children, by Dr. Hubert, with an account of the first year of the clinic's work at St. Thomas's is both interesting and informative.
In addition to these articles of which I have given some brief idea there are others on genitourinary, gynæcological, obstetric, orthopædic and ophthalmological subjects worthy of recommendation which contribute to the value of the book. Last but not least, I feel that the Editors should be congratulated on the excellent presentation of the book.

\section{HANDBOOK OF SKIN DISEASES.}

Revised by J. Kinnear. Fourth Edition. E. \& S. Livingstone, Edinburgh. 233 pp. and 86 illustrations of which 16 are in colour. 1939. Price 10s. 6d.

In revising Dr. Gardiner's now almost classical Handbook on Diseases of the Skin, Dr. Kinnear has adhered to the principle of providing a book dealing with essentials, and has avoided the introduction of controversial matter, reference and deference to the opinion of others, etc., etc. It is to be expected that Dr. Kinnear's views on a number of points are at variance with those of the original author, but he has done very rightly to refer to this in the preface only, thereafter giving himself a free hand. The resultant text is written in a strong key revealing a straightforwardness which is probably a feature of the writer's own handling of patients in general. Thus (p. 124), we read, that in the treatment of dermatitis artefacta, one should seek an opportunity for " a good straight talk with the patient." It is apparent that the author has personality, and knows when to put it into action for a therapeutic motive.

The author has omitted all, or nearly all, reference to monilia though a few lines are devoted to yeast infections. While the existence of some such parasite is now admitted by most, it seems that each dermatologist has his own idea of what a monilia should look like in either film or culture, and it is perhaps for this reason that Dr. Kinnear has thought it best to omit all mention of a word, which a fortiori, must be most confusing to the student and non-specialist. Another omission is the treatment of hypertrichosis menti in women. Whatever one's attitude to this difficult problem may be, some reference as to what to do or say to such patients would have been desirable, as all practitioners are faced with the situation, not very infrequently.

If the book has any fault it is that of all small books, namely: that it is the common diseases which suffer compression and not the rare. Thus pityriasis rubra pilaris, which even the specialist rarely sees, occupies as much space as pityriasis rosea. On the other hand, it must be said that the information on the latter condition if not extensive - thirty lines_is fairly adequate for a disease which, though common, is not serious.

Coloured and plain photographs as well as diagrammatic representations of micro-sections are good, plentiful and illuminating. This, together with the excellent print and paper, and above all the easy conversational style of the text, make the book one of the very best of the small books published on dermatology. 